\title{
Optimizing Callus Induction and Proliferation for Agrobacterium-mediated Transformation of Brachypodium distachyon
}

\author{
A. Behrouri ${ }^{1,4 *}$, A. Perochon ${ }^{1,2,3}$, F.M. Doohan ${ }^{1,2,3}$ and C.K.-Y. NG ${ }^{1,2,3}$ \\ ${ }^{1}$ School of Biology and Environmental Science, University College Dublin, Belfield, Dublin 4, Ireland \\ ${ }^{2}$ UCD Centre for Plant Science, University College Dublin, Belfield, Dublin 4, Ireland \\ ${ }^{3}$ UCD Earth Institute, University College Dublin, Belfield, Dublin 4, Ireland \\ ${ }^{4}$ Department of Agroecology, Darab College of Agriculture and Natural Resources, \\ Shiraz University, Darab, Iran
}

(Received 2 February 2017; Accepted 13 September 2017)

\begin{abstract}
Brachypodium distachyon has emerged as the model species for important temperate grass crops such as wheat and barley and the genome of the $B$. distachyon community inbred line $\mathrm{Bd} 21$ has been sequenced. Methods for tissue culture and Agrobacterium-mediated transformation have been developed for this model grass as a resource for reverse genetics and functional genomic analyses. In order to obtain a high quantity and quality of compact embryogenic callus (CEC) in B. distachyon, it is important to examine and optimize the optimal concentration of the auxin 2,4-D (dichlorophenoxyacetic acid) to use in both callus induction and callus proliferation media. Here, we investigated the effects of different concentrations of 2,4-D on callus induction and callus proliferation of $B$. distachyon $\mathrm{Bd} 21$. Our results showed that $2.5 \mathrm{mg} \mathrm{l}^{-1} 2,4-\mathrm{D}$ is an optimal concentration to use for both callus induction and proliferation, although $5.0 \mathrm{mg} \mathrm{l}^{-1}$ may also be used for callus proliferation. Additionally, the suitability of hygromycin or bialaphos as selectable markers was examined and results indicated that hygromycin is significantly more efficient than bialaphos when using the Agrobacterium-mediated transformation system.
\end{abstract}

Keywords: Brachypodium distachyon, immature embryos, callus induction and proliferation, Agrobacterium-mediated transformation, selectable marker

\section{Introduction}

In recent years, Brachypodium distachyon has become the new model species for temperate grass research and its genome was sequenced in 2010 (The International Brachypodium Initiative 2010). Although $B$. distachyon is not agriculturally important, it is a useful experimental plant model for understanding the genetics, cell and molecular biology, and physiological responses of temperate monocotyledonous plants. Its suitability as a temperate grass model for tissue culture was first investigated in the mid-1990s, testing different media and conditions for their suitability in generating and sub-culturing of embryogenic callus and cell suspension cultures from various explants (Bablack et al. 1995).

\footnotetext{
*Corresponding author; Email: behpoori@shirazu.ac.ir
} 
Importantly, Christensen et al. (2005) showed that there is a high level of genetic variation among $B$. distachyon accessions, and Vogel et al. (2006b) evaluated 29 different accessions of $B$. distachyon and conducted inbreeding experiments before identifying the diploid inbred line $\mathrm{Bd} 21$ as the community standard for genome sequencing due to its potential for both embryogenic callus production and plant regeneration (Vogel et al. 2006a). Since then, B. distachyon $\mathrm{Bd} 21$ has been used by several research groups to develop and improve methods for Agrobacterium tumefaciens-mediated transformation (Vogel et al. 2006b; Vogel and Hill 2008; Vain 2008; Alves et al. 2009).

The first attempts for determining suitable explants and medium for Brachypodium tissue culture showed that immature embryos and Linsmaier and Skoog (LS) agar plates supplemented with $2.5 \mathrm{mg}^{-1}$ synthetic auxin, 2,4-dichlorophenoxyacetic acid (2,4-D), were the best explants and media, respectively, for generating Brachypodium embryogenic callus (Bablack et al. 1995). Draper et al. (2001) examined the combined effect of embryo size/culture media on agar plates and they found that the best results were obtained when small embryo sizes $(0.3$ to $0.7 \mathrm{~mm})$ were used with LS media using 2.5 $\mathrm{mg} \mathrm{l}^{-1} 2,4-\mathrm{D}$. Two types of calli were produced after 2 to 3 weeks. Type I callus was soft, watery and more translucent and was not suitable for regeneration. Creamy-white, type II compact embryogenic (CEC) callus, which was dry and friable, was amenable to Agrobacterium tumefaciens-mediated transformation and subsequent regeneration. Furthermore, Draper et al. (2001) showed that embryogenic callus can be transformed by biolistic transformation and subsequently regenerated into mature plants. Thereafter, there have been improvements made to the protocol for the Agrobacterium-mediated transformation of $B$. distachyon although there have been considerable differences among the various protocols used (Vogel and Hill 2008; Garvin et al. 2008; Pacurar et al. 2008; Vain and Thole 2009; Vain et al. 2008; Alves et al. 2009; Thole et al. 2011). They used 2.5mg $1^{-1}$ 2,4-D for callus initiation. Hunt et al. (2014) established B. distachyon cell suspension cultures using $7.5 \mathrm{mg} \mathrm{1}^{-1} 2$,4-D for callus initiation. Due to inter-laboratory differences, it is important to empirically determine the optimal conditions for callus induction and proliferation before Agrobacterium-mediated transformation.

There are different ways for selection and screening of transgenic calli by using reporter genes like uidA or gfp (An et al. 2016). Also, both HPT (hygromicin B resistance) and $B A R$ genes (Basta ${ }^{\circledR} /$ Bialaphos resistance) can be used as selectable markers (Thole and Vain 2012; Steinwand et al. 2013; Bragg et al. 2012, 2015). Collier et al. (2016) recently reported the use of $A$. rhizogenes strain $18 \mathrm{r} 12 \mathrm{v}$ instead of $A$. tumefacience and application of paromomycin as selective agent in successful transformation of $B$. distachyon and B. sylvaticum. Păcurar et al. (2008) used the binary vector, pWBV-Ds-Ubi-bar-Ds carrying a T-DNA that includes both $B A R$ and $H P T$-resistance genes. They reported high transformation efficiency (57\%) using bialaphos solely, as compared to applying both bialaphos and hygromycin $(27 \%)$ or only hygromycin $(35 \%)$.

In this study, we examined different levels of 2,4-D $\left(0,2.5,5.0,7.5\right.$, and $\left.9.0 \mathrm{mg} \mathrm{l}^{-1}\right)$ on callus induction, and the subsequent propagation of compact embryogenic callus (CEC). We showed that 2,4-D at a concentration of between 2.5 to $5.0 \mathrm{mg} \mathrm{l}^{-1}$ were optimal for induction and proliferation of CEC from B. distachyon $\mathrm{Bd} 21$ prior to Agrobacterium- 
mediated transformation. Also, the suitability of hygromycin and bialaphos as selectable markers were examined. We used about 6300 B. distachyon $\mathrm{Bd} 21$ embryogenic calli for Agrobacterium-mediated transformation, and the results showed that transformation efficiency varied from 5 to $88 \%$ for regenerated plantlets.

\section{Materials and Methods}

\section{Seed germination and plant growth}

Seeds of Brachypodium distachyon inbred line Bd21 (kindly provided by Dr. David Garvin, USDA-ARS-Plant Science Research, St. Paul, MN 55108, USA) were germinated and plants were grown as previously described (Hunt et al. 2014).

\section{Callus induction and proliferation}

Immature embryos of $B$. distachyon inbred line $\mathrm{Bd} 21$ were used for callus induction 4 to 6 weeks following transfer of the seedlings to soil. The method used for callus induction was according to Vogel and Hill (2008) and Hunt et al. (2014). After 3 weeks, the embryos that produced yellow healthy embryogenic callus and those that produced compact embryogenic callus (CEC) were evaluated in each treatment in 3 experimental replicates. Embryos which produced a high mixture of watery, non-embryogenic callus with small patches of embryogenic callus or showed necrosis were considered as non-embryogenic. The mean percentage of the embryos where CEC were observed was calculated and analysis of variance (ANOVA) was carried out to determine significant differences among the different concentrations of 2,4-D. Additionally, means comparison test using Tukey's method was conducted to identify the significant differences between the means. The effect of 2,4-D on callus proliferation was assessed using CEC which were grown on 2.5 $\mathrm{mg} \mathrm{l}^{-1} 2,4-\mathrm{D}$. The effect of 5 concentrations of 2.4-D on callus proliferation was assessed $\left(0,2.5,5.0,7.5\right.$, and $\left.9.0 \mathrm{mg} \mathrm{l}^{-1}\right)$. The percentages of the calli which produced healthy yellow callus with no necrosis or root differentiation were calculated per plate. Calli that were smaller than $3 \mathrm{~mm}$ were not considered as having proliferated. The mean percentages of the proliferated calli were calculated with 3 experimental replicates (Table S1*).

\section{Vectors and the use of HPT and BAR genes as selectable markers}

Vectors including pPZP-RCS2, pEU334AN (Eamens et al. 2004), pCAMBIA 1305.1 which contain HPT gene and pANIC6E and pAM-PAT-TaFROG-YFP which contain $B A R$ gene were used in this study (Table S2). It is generally believed that the transformation efficiency declines when plasmid size increases (Hanahan 1983; Mohammadhassan et al. 2014) although the effects of vector size on Agrobacterium-mediated transformation efficiency have not been extensively studied. Vectors in this study varied in size from pPZP-RCS2 (4603bp) to pEU334AN (21188bp). Also, pAM-PAT-TaFROG-YFP and

\footnotetext{
*Further details about the Electronic Supplementary Material (ESM) can be found at the end of the article.
} 
pANIC6E belong to the GATEWAY group of vectors (Gateway® technology). Hygromycin was used as the selectable agent at a concentration of $40 \mathrm{mg} \mathrm{l}^{-1}$ for selection of putative transgenic calli and regenerated plantlets. When pANIC6E and pAM-PAT-TaFROGYFP which contain BAR gene were used, Bialaphos (SC-280620, Santa Cruz Biotechnology) at a concentration of $4 \mathrm{mg}^{-1}$ was used in the same media instead of hygromycin. The effectiveness of bialaphos and hygromycin were examined for Agrobacterium-mediated transformation of $B$. distachyon $\mathrm{Bd} 21$.

\section{Transformation of B. distachyon calli using Agrobacterium tumefaciens}

Callus induction and formation was conducted according to (Vogel and Hill 2008; Alves et al. 2009; Hunt et al. 2014). After 6 weeks of embryo culture and embryogenic callus multiplication on LS medium (LS $4.4 \mathrm{~g} \mathrm{l}^{-1}, 3 \%(\mathrm{w} / \mathrm{v})$ maltose $2.5 \mathrm{mg} \mathrm{l}^{-1}$ 2,4-D, $0.6 \mathrm{mg} \mathrm{l}^{-1}$ $\mathrm{CuSO}_{4}$, and $0.8 \%(\mathrm{w} / \mathrm{v})$ plant cell culture tested agar, $\left.\mathrm{pH} 5.8\right)$, CECs were inoculated with A. tumefaciens strain AGL1 $\left(\mathrm{OD}_{600}=1\right)$ harbouring pPZP-RCS2, pEU334AN, pCAMBIA 1305.1 in LS medium supplemented with $45 \mathrm{mg} \mathrm{l}^{-1}$ acetosyringone (AS). Desiccated calli were co-cultured (Cheng et al. 2003, 2004) on LS medium (4.4 $\mathrm{mg} \mathrm{l}^{-1} \mathrm{LS}+60 \mathrm{mg} \mathrm{l}^{-1}$ $\mathrm{AS}+30 \mathrm{~g} \mathrm{l}^{-1}$ sucrose $+30 \mathrm{~g} \mathrm{l}^{-1}$ glucose) without $\mathrm{CuSO}_{4}$ for $2 \mathrm{~d}$. Glucose and sucrose in the medium help the growth of $A$. tumefaciens and consequently can improve transformation efficiency (Vogel and Hill 2008; Alves et al. 2009). Calli were then transferred to selection medium containing $4.4 \mathrm{~g} \mathrm{l}^{-1} \mathrm{LS}+0.6 \mathrm{mg} \mathrm{l}^{-1} \mathrm{CuSO}_{4}+2.5 \mathrm{mg} \mathrm{l}^{-1} 2,4-\mathrm{D}+40$ $\mathrm{mg} \mathrm{l}^{-1}$ hygromycin $+275 \mathrm{mg} \mathrm{l}^{-1}$ timentin $+0.8 \%(\mathrm{w} / \mathrm{v})$ agar in a $25{ }^{\circ} \mathrm{C}$ incubator for 2 periods of 3 weeks. Yellow and healthy calli were then transferred to regeneration medium containing $4.4 \mathrm{~g} \mathrm{l}^{-1} \mathrm{LS}, 250 \mathrm{mg} \mathrm{l}^{-1}$ kinetin, $40 \mathrm{mg} \mathrm{l}^{-1}$ hygromycin, $275 \mathrm{mg} \mathrm{l}^{-1}$ timentin, and $0.8 \%(\mathrm{w} / \mathrm{v})$ agar without $\mathrm{CuSO}_{4}$.

After about 2 weeks, small shoots were observed and well-developed plantlets were transferred to sterile soil, a mixture of 2:1 of Shamrock Multipurpose Compost (Bord na Móna Horticulture, Ireland) to vermiculite (Sinclair, UK) and grown as previously described (Hunt et al. 2014). In order to confirm the presence of T-DNA in the genomic DNA of putative transgenic plants, transformants were verified by PCR using primers designed to amplify the hygromycin resistance gene (HPT) (ABTHygFw: 5'-AAAAGCCTGAACTCACCGC-3', ABTHygRv: 5'- TCGTCCATCACAGTTTGCC-3'). The total volume of PCR reaction was $20 \mu \mathrm{l}$ including 1U Promega Taq Polymerase, 1X Green Go-Taq Buffer, $1.5 \mathrm{mM} \mathrm{Mgcl} 2,0.1 \mathrm{mM}$ dNTPs and $0.25 \mu \mathrm{M}$ of each forward and reverse primers with $50 \mathrm{ng}$ Brachypodium genomic DNA. PCR reaction was performed in a G-Storm GS1 thermal cycler machine. PCR reaction consisted of an initial step $\left(95{ }^{\circ} \mathrm{C}\right.$ for $3 \mathrm{~min}$ ); 30 cycles $\left(95^{\circ} \mathrm{C}\right.$ for $30 \mathrm{sec}, 52^{\circ} \mathrm{C}$ for $1 \mathrm{~min}$ and $72{ }^{\circ} \mathrm{C}$ for $1 \mathrm{~min}$ ); final step $\left(72{ }^{\circ} \mathrm{C}\right.$ for $\left.10 \mathrm{~min}\right)$. Also, in order to confirm the presence of the construct carrying the Bialaphos gene, primers (pAM-PromFw: 5'- TCCCACTATCCTTCGCAAGACC-3', pAM-TaFROGRv 5'-GAATTTCCTAGAGCTGATCTTATGG-3') were used. PCR was performed in a $20 \mu \mathrm{l}$ reaction containing $1 \mathrm{U}$ TaKaRa LA Taq (Code No. RR002M) and $1 \times$ LA PCR Buffer 11 (Mg2+ plus), $0.4 \mathrm{mM}$ dNTPs and $0.25 \mu \mathrm{M}$ of each of forward and reverse primers with $50 \mathrm{ng}$ brachypodium genomic DNA. PCR was performed in a Peltier 
thermal cycler DNA engine and the PCR program consisted of an initial step $\left(94{ }^{\circ} \mathrm{C}\right.$ for 5 min); 35 cycles $\left(94^{\circ} \mathrm{C}\right.$ for $10 \mathrm{sec}, 60^{\circ} \mathrm{C}$ for $35 \mathrm{sec}, 68^{\circ} \mathrm{C}$ for $1 \mathrm{~min}$ ) and a final extension step $\left(72{ }^{\circ} \mathrm{C}\right.$ for $\left.5 \mathrm{~min}\right)$. The amplification products were visualised using ethidium bromide or SafeView Nucleic Acid Stain (NBS-SV1) staining following electrophoretic separation on $1 \%$ agarose gel.

\section{Results}

Optimization of compact embryogenic callus (CEC) induction and proliferation from immature embryos of B. distachyon Bd21

Callus quality and quantity are pivotal factors for B. distachyon tissue culture and in vitro transformation, respectively, and the number of transgenic plants produced is dependent on the ability to generate sufficient quantities of good quality calli. The mean percentage of CEC induced from immature embryos were calculated and statistical analysis (ANOVA) showed a significant difference $(p \leq 0.01)$ in callus induction at different concentrations of 2,4-D $\left(0,2.5,5.0,7.5\right.$, and $\left.9.0 \mathrm{mg} \mathrm{l}^{-1}\right)$ in the culture medium. As can be seen from Table S1, there was no CEC induction in the absence of 2,4-D in the medium, and all of the cultured embryos started to differentiate and produced roots and hypocotyls (Fig. $\mathrm{S} 1 \mathrm{~A})$. The application of $2.5 \mathrm{mg} \mathrm{l}^{-1} 2,4-\mathrm{D}$ significantly $(p \leq 0.01)$ increased the induction of CEC and the highest percentage of callus induction was observed at this concentration $(67 \%)$. However, increasing the $2,4-\mathrm{D}$ concentration to $5.0 \mathrm{mg}^{-1}$ did not result in an increase in CEC induction, but rather resulted in a significantly lower level of callus induction $(45 \%)(p \leq 0.01)$. Increasing the $2,4-\mathrm{D}$ concentrations to 7.5 and $9.0 \mathrm{mg} \mathrm{l}^{-1}$ further reduced the percentage of CEC induction, although the differences observed were not significant between 5.0 and $7.5 \mathrm{mg} \mathrm{l}^{-1}$ of 2,4-D in the induction media. The application of $9.0 \mathrm{mg} \mathrm{l}^{-1} 2,4-\mathrm{D}$ resulted in significantly lower $(p \leq 0.01)$ CEC induction $(22 \%)$ (Table S1 and Fig. S1). These results showed that $2.5 \mathrm{mg} \mathrm{l}^{-1}$ is the optimal concentration of 2,4-D for induction of CEC from immature embryos of $B$. distachyon $\mathrm{Bd} 21$.

For callus proliferation, calli were sub-cultured from CEC that had been cultured on medium supplemented with $2.5 \mathrm{mg}^{-1} 2$,4-D onto medium with varying concentrations of 2,4-D ranging from, $2.5,5.0,7.5$, to $9.0 \mathrm{mg} \mathrm{l}^{-1}$. The percentages of the calli which produced healthy yellow callus with no necrosis or root differentiation were calculated per plate. Calli which were smaller than $3 \mathrm{~mm}$ were not considered as having undergone proliferation. Statistical analysis (ANOVA) of the results obtained from sub-culturing CEC onto various concentrations of 2,4-D showed significant differences $(p<0.01)$ between the treatments (Table S1). Only $32 \%$ of the CEC sub-cultured on the medium without 2,4-D produced yellow healthy calli, with the rest of the calli showing either root differentiation or necrosis (Fig. S2A). Increasing the level of 2,4-D to $2.5 \mathrm{mg} \mathrm{l}^{-1}$ significantly increased the percentage of healthy CEC to $80 \%$ (Table S1). A further increase in the concentration of 2,4-D to $5 \mathrm{mg} \mathrm{l}^{-1}$ resulted in a slight decrease in calli proliferation $(75 \%)$, however, this reduction $(5 \%)$ was not significant. Increasing the concentrations of 2,4-D to higher levels $\left(7.5\right.$ and $\left.9.0 \mathrm{mg}^{-1}\right)$ significantly $(p \leq 0.01)$ reduced CEC prolifera- 
tion to 45 and $47 \%$, respectively. The results showed that different concentrations of 2,4$\mathrm{D}$ can have profound effects on CEC induction and development (Table S1 and Fig. S1). All the embryos cultured in the absence of 2,4-D $\left(0 \mathrm{mg} \mathrm{l}^{-1}\right)$ started to produce roots and shoots, and produced neither embryogenic nor non-embryogenic calli during the 3-week induction period (Fig. S1A). Healthy, yellow and compact embryogenic calli (CEC) were consistently induced in medium supplemented with $2.5 \mathrm{mg} \mathrm{l}^{-1} 2,4-\mathrm{D}$ (Fig. S1B). Although embryogenic calli were also induced at $5 \mathrm{mg} \mathrm{l}^{-1} 2,4-\mathrm{D}$, less of the calli mass appear to consist of CEC (Fig. S1C). Induction medium containing $7.5 \mathrm{mg}^{-1} 2,4-\mathrm{D}$ resulted in calli consisting of a mixture of embryogenic and non-embryogenic callus and less calli proliferation (Fig. S1D) compared to lower concentrations $\left(2.5\right.$ and $\left.5.0 \mathrm{mg} \mathrm{l}^{-1}\right)$ of 2,4-D (Fig. S1B and S1C). Induction medium supplemented with $9.0 \mathrm{mg} \mathrm{l}^{-1} 2,4-\mathrm{D}$ resulted in watery and non-embryogenic callus (Fig. S1E).

The growth rate and proliferation of embryogenic calli following subculturing was tested on medium supplemented with different concentrations of 2,4-D $(0,2.5,5.0,7.5$, and $9.0 \mathrm{mg}^{-1}$ ). Good growth of calli (compact, yellow and embryogenic) obtained in solid medium supplemented with $2.5 \mathrm{mg}^{-1}$ of 2,4-D was compared to calli growth on other concentrations of 2,4-D (Fig. S2A). Visual observations indicated that the size of the calli were larger on solid medium supplemented with $2.5 \mathrm{mg} \mathrm{l}^{-1}$ of 2,4-D compared to calli cultured on $0,7.5$, and $9.0 \mathrm{mg} \mathrm{l}^{-1}$ of 2,4 -D. It was not possible to distinguish by visual observations, calli grown on 2.5 or $5.0 \mathrm{mg} \mathrm{l}^{-1}$ 2,4-D (Fig. S2B and S2C). However, some necrosis was observed in calli cultured on $5.0 \mathrm{mg} \mathrm{l}^{-1} 2,4-\mathrm{D}$ (see Fig. S2C). Root differentiation was observed in plates that did not contain any 2,4-D (Fig. S2A). No root differentiation was observed in all plates supplemented with 2,4-D at 2.5, 5.0, 7.5 and 9.0 $\mathrm{mg}^{-1}$ (Fig. S2B, S2C, S2D and S2E). Calli remained yellow when cultured on medium supplemented with $2.5 \mathrm{mg} \mathrm{l}^{-1} 2,4-\mathrm{D}$, and did not show any necrosis (Fig. S2B). For all subsequent experiments for callus induction and proliferation, a 2,4-D concentration of $2.5 \mathrm{mg} \mathrm{l}^{-1}$ was used, and each week 200 to 300 embryogenic calli were generated for transformation.

Although, some researchers showed that the use of hygromycin appeared to be more efficient than bialaphos for selection of transformed calli (Christiansen et al. 2005; Pacurar et al. 2008; Vain et al. 2008; Alves et al. 2009), others have used bialaphos as the preferred selectable agent in high-throughput Agrobacterium-mediated transformation of B. distachyon (Table S3). In order to identify the best selectable agent, we compared the application of hygromycin or bialaphos for Agrobacterium-mediated transformation of B. distachyon $\mathrm{Bd} 21$.

Different concentrations of hygromycin $\left(0,20,30\right.$ and $\left.40 \mathrm{mg}^{-1}\right)$ and bialaphos $(0,2$, 3,4 and $\left.6 \mathrm{mg} \mathrm{l}^{-1}\right)$ were tested in selection medium on putative transgenic $B$. distachyon $\mathrm{Bd} 21$ calli. The results demonstrated that the concentration of $40 \mathrm{mg} \mathrm{l}^{-1}$ of hygromycin and $4 \mathrm{mg} \mathrm{l}^{-1}$ of bialaphos produced the best results (one experiment for hygromycin and one for bialaphos each with 4 experimental replicates). Therefore, these concentrations of hygromycin and bialaphos were used in all experiments. Table S2 showed the results of transformation efficiency of $B$. distachyon $\mathrm{Bd} 21$ based on regenerated plantlets. Five vectors were examined in this study (pPZP-RCS2, pEU334AN, pCAMBIA 1305.1 which 
contain HPT gene, and pANIC6E and pAM-PAT-TaFROG-YFP which contain $B A R$ gene). The results indicated that the highest transformation percentage was obtained using pEU334AN (88\%), followed by pCAMBIA 1305.1 (81\%), pPZP-RCS2 (71\%), pAMPAT-TaFROG-YFP (27\%), and pANIC6E (19\%). Based on the results in Table S2, the average of transformation efficiency in the experiments containing hygromycin $(\sim 64 \%)$ was significantly greater $(t$-test, $p<0.01)$ than the average of transformation efficiency using bialaphos $(13 \%)$.

In addition to the significant differences in the transformation efficiency, there were significant visual differences between the calli growing in petri plates under hygromycin or bialaphos selection. During the $2 \times 3$ weeks of selection period using hygromycin as the selective antibiotic, most of the calli contained brown and necrotic sectors, indicating dying non-transgenic section of the calli. The growing healthy and yellowish part of the calli which were transferred to regeneration media were regenerated to plantlets with the average efficiency of $\sim 63 \%$. Non-transformed calli sections were visibly brown or necrotic. In contrast, under bialaphos selection, some of the calli stopped growing or had a very slow growing pattern over $2 \times 3$ weeks of selection period with no, or few brown and necrotic sections. Furthermore, some of the calli which even continued to grow did not regenerate into plantlets when transferred to regeneration medium. This pattern of calli selection under the application of bialaphos was not as straightforward compared to hydromycin for identifying transgenic calli. Hygromycin B appeared to be a better plant selection agent compared to bialaphos. Overall, about 6300 B. distachyon $\mathrm{Bd} 21$ embryogenic calli were used for transformation. Our data demonstrated variable transformation efficiency for regenerated plantlets that ranged from 5 and $88 \%$ (Table 1). Altogether, 1134 putative transgenic lines were obtained of which about $25 \%$ (287) of the small plantlets died after transfer to the soil or were sterile and did not produce any seeds. The various steps from callus induction to transformation and regeneration are summarised in the schematic flow chart in Fig. S3.

\section{Validation by PCR of the T-DNA insertions}

PCR analysis targeting the hygromycin resistance gene (HPT) was used to ascertain the presence of T-DNA in genomic DNA isolated from a sub-set (9) of the transgenic plants. The results showed the presence of a clear band at the expected size in 6 of the 9 putative transgenic plants, indicating the presence of the T-DNA in these plants. There was another fainter band of a slightly smaller molecular weight in all amplifications and this is

Table 1. Transformation efficiency of $B$. distachyon $\mathrm{Bd} 21$ from callus to mature plants

\begin{tabular}{|l|c|c|c|c|}
\hline & Lowest \% & Highest \% & Average \% & Total No. \\
\hline Callus & 0 & 83 & 46 & 6300 \\
\hline Regeneration & 5 & 88 & 63 & 2750 \\
\hline Plant & 71 & 100 & 84 & 1134 \\
\hline Fertile/Partial Fertile & - & - & - & 847 \\
\hline
\end{tabular}


likely to be due to non-specific amplification (as it is also present in the positive control using the vector, pEU33AN as the template) (Fig. S4A). Similarly, 9 transgenic lines resistant to the bialaphos carrying the $B A R$ gene as a selectable marker were confirmed by PCR (Fig. S4B) for the integration of pAM-PAT-P35S-TaFROG-YFP construct into transgenic Brachypodium distachyon Bd21 plants. Moreover, confocal laser scanning microscopy showed the correct expression of TaFROG-YFP in Brachypodium distachyon cells within distinct nuclear bodies (Fig. S5) as described previously in wheat (Perochon et al. 2015). The similarity in subcellular localization of fluorescent protein-tagged wheat proteins in both wheat and $B$. distachyon further supports the usefulness of $B$. distachyon as an experimental system for determining the subcellular localization of temperate grass proteins.

\section{Discussion}

While $B$. distachyon has emerged as a plant model for temperate grasses, the development of an efficient transformation protocol for $B$. distachyon is highly significant for any functional genomics research. This includes optimization of protocols for callus induction and proliferation. Although methods for callus induction and proliferation have already been developed by several researchers (Draper et al. 2001; Vogel and Hill 2008; Alves et al. 2009), optimization is necessary due to potential inter-laboratory differences in optimal conditions for tissue culture.

As successful induction of compact embryogenic callus (CEC) from immature embryos from B. distachyon is dependent on auxin concentration (Draper et al. 2001; Christiansen et al. 2005; Vogel et al. 2006b; Păcurar et al. 2008; Vain et al., 2008; Vogel and Hill 2008; Alves et al. 2009), different levels of 2,4-D, ranging from 0 to $9 \mathrm{mg} \mathrm{l}^{-1}$ were tested. The results showed that 2,4-D at a concentration of $2.5 \mathrm{mg}^{-1}$ is optimal for callus induction (Fig. S1), in agreement with previous studies that also reported an optimal 2,4$\mathrm{D}$ concentration of $2.5 \mathrm{mg} \mathrm{l}^{-1}$ for callus induction in B. distachyon $\mathrm{Bd} 21$ (Vogel et al. 2006b; Vain et al. 2008; Alves et al. 2009; Lee et al. 2011), B. distachyon Bd21-3 (Vogel and Hill 2008; Alves et al. 2009), and B. distachyon BDR018 (Păcurar et al. 2008). Christiansen et al. (2005) have also reported that a 2,4-D concentration of $2.5 \mathrm{mg} \mathrm{l}^{-1}$ is suitable for callus induction in 37 accessions of $B$. distachyon. Of the other concentrations of 2,4D tested, some of the calli differentiated roots, while others developed necrosis (Fig. S1). We were also guided by the protocol of Alves et al. (2009) by supplementing the medium with $\mathrm{CuSO}_{4}\left(0.6 \mathrm{mg} \mathrm{l}^{-1}\right)$ to promote embryogenic callus growth and reduce the possibility of regenerating albino plants. In addition, subculture of CECs longer than 6 weeks for transformation was not recommended due to unwanted somatic genetic variation and regeneration of albino plants (Alves et al. 2009). As such, CEC were periodically generated to ensure a constant supply for genetic transformation.

Additionally, 5-week old calli were grown and sub-cultured on different levels of 2,4$\mathrm{D}\left(0,2.5,5.0,7.5\right.$, and $\left.9.0 \mathrm{mg}^{-1}\right)$ to examine the quality and quantity of calli for subsequent transformation. Our results showed that 2,4-D concentrations of 2.5 and $5.0 \mathrm{mg} \mathrm{l}^{-1}$ were suitable for calli propagation and that both these 2,4-D concentrations produced the 
highest amounts of embryogenic calli (Fig. S2). However, it should be noted that some necrosis, evident from browning of calli, were observed when $5.0 \mathrm{mg} \mathrm{l}^{-1}$ of 2,4-D were used (Fig. S2C). Taking all these into consideration, it was decided that $2.5 \mathrm{mg} \mathrm{l}^{-1}$ of 2,4D should be used for all subsequent experiments.

The results of our experiments highlighted the usefulness of hygromycin as a selectable agent in Agrobacterium-mediated transformation of B. distachyon, and the use of bialaphos required further optimization. Another factor which needs to be considered more precisely in the future experiments is the type of promoter used for driving the selectable marker gene. Different constitutive promoters have been exploited to drive both HPT and $B A R$ genes by researchers. It is noteworthy to state that other factors can also affect the transformation efficiency like the type of promoter driving the selectable agent and the type of vector. So, it would be valuable to use different types of vectors including Gateway ${ }^{\circledR}$ vectors with different promoters and selectable agents for further experiments.

A gradual decrease (40:30:20 $\mathrm{mg} \mathrm{l}^{-1}$ ) in concentration of hygromycin is recommended with the help of reporter genes such as $g f p$. However, screening for GFP fluorescence appears to be of limited usefulness in our case because of the high level of autofluorescence in B. distachyon (data not shown). Consequently, we used a constant concentration of hygromycin $\left(40 \mathrm{mg} \mathrm{l}^{-1}\right)$ for selection of transformed calli and for regeneration of transgenic plantlets. After 3 weeks of culturing calli in selection medium, healthy and yellow calli were dissected and transferred to fresh selection medium. For calli larger than 3-4 $\mathrm{mm}$, the calli were divided into 2 or 3 smaller pieces. While this method was useful for maintaining transgenic calli, it should also be noted that this may lead to the regeneration of multiple identical transgenic lines.

In summary, the lowest and highest transformation efficiency for regenerated plantlets obtained in our experiments was 5 and $88 \%$ respectively with an average of $63 \%$. Different transformation efficiencies have been reported. For example, Vogel and Hill (2008) reported an average transformation efficiency of $41 \%$, while Păcurar et al. (2008), Lee et al. (2011), and Alves et al. (2009) reported average transformation efficiencies of 96\%, $80 \%$, and $90 \%$, respectively. Regardless of the transformation efficiency, the ability to generate a transgenic population for $B$. distachyon opens up the possibility for the wider scientific community to use this T-DNA tagged population for screening experiments to identify phenotypes associated with biotic or abiotic stresses, and developmental processes. Additionally, we also showed that $B$. distachyon is a useful experimental model for determining the subcellular localization of fluorescent-protein tagged wheat proteins.

\section{Acknowledgements}

This work is supported by Science Foundation Ireland (SFI) Research Frontiers Programme grants 06/RFP/GEN034 and 08/RFP/EOB1087 (to C.K.-Y.N.) and project Nos. 10/IN.1/B3028 and 14/1A/2508 (to A. P. and F.M. D.), and an Iranian Government Research Scholarship (to A.B.). 


\section{References}

Alves, S.C., Worland, B., Thole, V., Snape, J.W., Bevan, M.W., Vain, P. 2009. A protocol for Agrobacteriummediated transformation of Brachypodium distachyon community standard line $\mathrm{Bd} 21$. Nat. Protoc. 4:638649.

An, T., Cai, Y, Zhao, S., Zhou, J., Song, B., Bux, H., Qi, X. 2016. Brachypodium distachyon T-DNA insertion lines: a model pathosystem to study nonhost resistance to wheat stripe rust. Sci. Rep. 6:25510.

Bragg, J.N., Anderton, A., Nieu, R., Vogel, J.P. 2015. Brachypodium distachyon. In: Wang, K. (ed), Agrobacterium Protocols. Springer. New York, USA. pp. 17-33.

Bragg, J.N., Wu, J., Gordon, S.P., Guttman, M.E., Thilmony, R., Lazo, G.R., Gu, Y.Q, Vogel, J.P., 2012. Generation and characterization of the western regional research center Brachypodium T-DNA insertional mutant collection. PLoS ONE 7:e41916.

Bablak, P., Draper, J., Davey, M.R., Lynch, P.T. 1995. Plant regeneration and micropropagation of Brachypodium distachyon. Plant Cell Tiss. Org. 42:97-107.

Cheng, M., Hu, T., Layton, J., Liu, C.N., Fry, J.E. 2003. Desiccation of plant tissues post-Agrobacterium infection enhances T-DNA delivery and increases stable transformation efficiency in wheat. In Vitro Cell. Dev.P1. 39:595-604.

Cheng, M., Lowe, B.A., Spencer, T.M., Ye, X., Armstrong, C.L. 2004. Factors influencing Agrobacteriummediated transformation of monocotyledonous species. In Vitro Cell. Dev.- Pl. 40:31-45.

Christiansen, P., Andersen, C.H., Didion, T., Folling, M., Nielsen, K.K. 2005. A rapid and efficient transformation protocol for the grass Brachypodium distachyon. Plant Cell Rep. 23:751-758.

Collier, R., Bragg, J., Hernandez, B.T., Vogel, J.P., Thilmony, R. 2016. Use of Agrobacterium rhizogenes strain $18 \mathrm{r} 12 \mathrm{v}$ and paromomycin selection for transformation of Brachypodium distachyon and Brachypodium sylvaticum. Front. Plant Sci. 7:716.

Draper, J., Mur, L.A., Jenkins, G., Ghosh-Biswas, G.C., Bablak, P., Hasterok, R., Routledge, A.P. 2001. Brachypodium distachyon. A new model system for functional genomics in grasses. Plant Physiol. 127:1539-1555.

Eamens, A.L., Blanchard, C.L., Dennis, E.S., Upadhyaya, N.M. 2004. A bidirectional gene trap construct suitable for T-DNA and Ds-mediated insertional mutagenesis in rice (Oryza sativa L.). Plant Biotechnol. J. 2:367-380.

Garvin, D., Gu, Y., Hasterok, R., Hazen, S., Jenkins, G., Mockler, T., Mur, L., Vogel, J. 2008. Development of genetic and genomic research resources for Brachypodium distachyon, a new model system for grass crop research. Crop Sci. 48:S69-S84.

Hanahan, D. 1983. Studies on the transformation of Escherichia coli with plasmids. J. Mol. Biol. 166:557-580.

Hunt, D., Chambers, J.P., Behpouri, A., Kelly, S.P., Whelan, L., Piettrzykowska, M., Downey, F., Mccabe, P.F., Ng, C.K.Y. 2014. Brachypodium distachyon cell suspension cultures: establishment and utilization. Cereal Res. Commun. 42:58-69.

Lee, M.B., Jeon, W.B., Kim, D.Y., Bold, O., Hong, M.J., Lee, Y.J., Park, J.H., Seo, Y.W. 2011. Agrobacteriummediated transformation of Brachypodium distachyon inbred line $\mathrm{Bd} 21$ with two binary vectors containing hygromycin resistance and GUS reporter genes. J. Crop Sci. Biotechnol. 14:233-238.

Mohammadhassan, R., Kashefi, B., Shabanzadeh, Delcheh, K. 2014. Agrobacterium-based vectors: a review. Intl. J. Farm. Allied Sci. 3:1002-1008.

Păcurar, D.I., Thordal-Christensen, H., Nielsen, K.K., Lenk, I. 2008. A high-throughput Agrobacteriummediated transformation system for the grass model species Brachypodium distachyon L. Transgenic Res. 17:965-975.

Perochon, A., Jianguang, J., Kahla, A., Arunachalam, C., Scofield, S.R., Bowden, S., Wallington, E., Doohan, F.M. 2015. TaFROG encodes a pooideae orphan protein that interacts with SnRK1 and enhances resistance to the mycotoxigenic fungus Fusarium graminearum. Plant Physiol. 169:2895-906.

Steinwand, M.A., Young, H.A., Bragg, J.N., Tobias, C.M., Vogel, J.P. 2013. Brachypodium sylvaticum, a model for perennial grasses: transformation and inbred line development. PLoS ONE 8: 75180.

The International Brachypodium Initiative. 2010. Genome sequencing and analysis of the model grass Brachypodium distachyon. Nature 463:763-768. 
Thole, V., Peraldi, A., Worland, B., Nicholson, P., Doonan, J.H., Vain, P. 2011. T-DNA mutagenesis in BrachyIpodium distachyon. J. Exp. Bot. 63:567-576.

Thole, V., Vain, P. 2012. Agrobacterium-mediated transformation of Brachypodium distachyon. Transg. Plants 847:137-149.

Vain, P., Thole, V. 2009. Gene Insertion Patterns and Sites. In: Jones, H.D., Shewry, P.R. (eds), Transgenic Wheat, Barley and Oats: Production and Characterization Protocols Humana Press. Totowa, NJ, USA. pp. 203-226.

Vain, P., Worland, B., Thole, V., McKenzie, N., Alves, S.C., Opanowicz, M., Fish, L.J., Bevan, M.W., Snape, J.W. 2008. Agrobacterium-mediated transformation of the temperate grass Brachypodium distachyon (genotype Bd21) for T-DNA insertional mutagenesis. Plant Biotechnol. J. 6:236-245.

Vogel, J.P., Gu, Y.Q., Twigg, P., Lazo, G.R., Laudencia-Chingcuanco, D., Hayden, D.M., Donze, T.J., Vivian, L.A., Stamova, B., Coleman-Derr, D. 2006a. EST sequencing and phylogenetic analysis of the model grass Brachypodium distachyon. Theor. Appl. Genet. 113:186-195.

Vogel, J.P., Hill, T. 2008. High-efficiency Agrobacterium-mediated transformation of Brachypodium distachyon inbred line Bd21-3. Plant Cell Rep. 27:471-478.

Vogel, J.P., Garvin, D.F., Leong, O.M., Hayden, D.M. 2006b. Agrobacterium-mediated transformation and inbred line development in the model grass Brachypodium distachyon. Plant Cell Tiss. Org. 84:199-211.

\section{Electronic Supplementary Material (ESM)}

Electronic Supplementary Material (ESM) associated with this article can be found at the website of CRC at http://www.akademiai.com/content/120427/

Electronic Supplementary Table S1. Effects of different concentrations of 2,4-D on embryogenic callus induction and propagation of $B$. distachyon $\mathrm{Bd} 21$

Electronic Supplementary Table S2. Transformation efficiency of B. distachyon Bd21 based on regenerated plantlets

Electronic Supplementary Table S3. Genetic transformation reports on Brachypodium distachyon

Electronic Supplementary Figure S1. Immature embryos of B. distachyon grown on medium with different concentrations of 2,4-D. (A) no 2,4-D, (B) 2.5, (C) 5.0, (D) 7.5, and (E) $9.0 \mathrm{mg} \mathrm{l}^{-1}$. White arrows indicate compact embryogenic callus (CEC). Scale bar $=1 \mathrm{~cm}$

Electronic Supplementary Figure S2. Embryogenic callus of B. distachyon grown on medium with different concentrations of 2,4-D. (A) no 2,4-D, (B) 2.5, (C) 5.0, (D) 7.5, and (E) $9.0 \mathrm{mg} \mathrm{l}^{-1}$. White arrows indicate differentiated or necrotic cells. Scale bar $=1 \mathrm{~cm}$

Electronic Supplementary Figure S3. Schematic representation of Agrobacterium-mediated transformation of Brachypodium distachyon

Electronic Supplementary Figure S4. Molecular characterization of Brachypodium transgenic lines. Verification by PCR of the insertion of the T-DNA construction carrying (A) the hygromycin (HPT) or (B) Bialaphos $(B A R)$ resistance genes in 9 putative transgenic lines (lanes 1-9). The wild type plant B. distachyon Bd21 (lane 10) and the vector utilised for the transformation (lane 11) were used as a PCR positive or negative control respectively. M: molecular weight marker

Electronic Supplementary Figure S5. Confocal laser scanning microscopy of TaFROG-YFP in Brachypodium distachyon. Stable Brachypodium leaves overexpressing TaFROG-YFP were analysed. TaFROG-YFP showed a punctate distribution within the nucleus, consistent with the distribution of TaFROG-YFP in wheat cells.

Scale bar $=10 \mu \mathrm{m}$ 